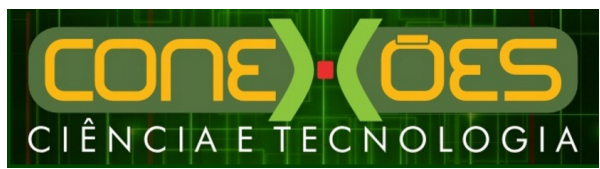

\title{
EVENTOS RELIGIOSOS: A FESTA DE NOSSA SENHORA DAS CANDEIAS E SEUS IMPACTOS NOS MEIOS DE HOSPEDAGEM DE JAGUARIBE - CEARÁ
}

\author{
Victor Hugo Santos de Castro, Francisca Erisnete Gomes de Lima \\ ${ }^{1}$ Instituto Federal de Educação, Ciência e Tecnologia do Ceará - IFCE \\ <vsantosdecastro@yahoo.com.br>, <erisnetelima@ hotmail.com>
}

DOI: 10.21439/conexoes.v11i5.1249

\begin{abstract}
Resumo. Este estudo aborda os eventos religiosos, em especial a festa de Nossa Senhora das Candeias em Jaguaribe-Ceará. A pesquisa teve como objetivo analisar os impactos da festividade nos meios de hospedagem no referido cenário. Os objetivos específicos foram: avaliar as relações dos meios de hospedagem com a equipe responsável pelo evento religioso; comparar a taxa de ocupação dos meios de hospedagem no período da festa com os demais meses do ano; identificar as estratégias de marketing utilizadas pelos meios de hospedagem na ocasião festiva; verificar forças e fraquezas dos meios de hospedagem na hospitalidade do hóspede e a visão do gestor quanto ao mercado hoteleiro. Quanto à metodologia, a pesquisa teve uma abordagem qualitativa, utilizando a entrevista com instrumento para a obtenção dos dados, a mesma foi gravada e transcrita para posterior análise. A pesquisa aponta como resultados, a elevação da taxa de ocupação dos meios de hospedagem na ocasião da festividade, a falta de comunicação entre a equipe organizadora do evento e os meios de hospedagem, poucas estratégias de marketing que corroborem para atrair mais visitantes e potenciais clientes, a importância dada à hospitalidade pelos gestores na estada dos hóspedes, visão limitada da gestão dos empreendimentos hoteleiros quanto à hotelaria da região. O estudo concluiu que a Festa de Nossa Senhora das Candeias contribui para uma maior visibilidade do município, fomentando o turismo e a economia do local, mas que estratégias devem ser adotadas para que o evento ganhe proporções maiores e se torne referência.
\end{abstract}

Palavras-chaves: Eventos religiosos. Nossa Senhora das Candeias. Meios de hospedagem.

Abstract. This study deals with religious events, especially the Nossa Senhora das Candeias festivity in Jaguaribe-Ceará. The research had as objective to analyze the impacts of the feast in the means of lodging in the referred scenario. The specific objectives were: to evaluate the relations of the means of lodging with the team responsible for the religious event; compare the rate of occupation of the means of lodging in the period of the party with the other months of the year; identify the marketing strategies used by the hosting media on the festive occasion; check the strengths and weaknesses of the lodging facilities in the guest's hospitality and the manager's view of the hotel market. As for the methodology, the research had a qualitative approach, using the interview with an instrument to obtain the data, it was recorded and transcribed for later analysis. The research points to results of the increase in the occupancy rate of the lodging facilities at the time of the festival, the lack of communication between the organizing team of the event and the means of hosting, few marketing strategies that corroborate to attract more visitors and potential clients, The importance given to hospitality by the managers in the stay of the guests, limited view of hotel management in the region's hotels. The study concluded that the Nossa Senhora das Candeias festivity contributes to a greater visibility of the municipality, fomenting the tourism and the local economy, but what strategies should be adopted so that the event gains larger proportions and becomes a reference.

Keywords: Religious Events. Nossa Senhora das Candeias. Hosting means. 


\section{INTRODUÇÃO}

Evento é um encontro de pessoas, com data e local definidos, com o intuito de discutir, debater ou celebrar um momento. As características de um evento irão depender do seu público-alvo, assim como da sua tipologia. Esta, engloba os eventos, a saber: técnicoscientíficos, comerciais, culturais, políticos, sociais, esportivos, gastronômicos, religiosos e outros.

Os eventos são importantes para a economia de uma cidade, pois podem ser considerados como uma estratégia de marketing para dar mais visibilidade a determinada região, e, assim, corroborar com o desenvolvimento local, gerando empregos formais e informais para a comunidade.

Os eventos movimentam o ramo hoteleiro, além de outras organizações atuantes no âmbito do turismo, como bares e restaurantes, casas de câmbio, equipamentos de lazer e outros. Quanto aos meios de hospedagem, quando há um evento em qualquer cidade, a taxa de ocupação tende a aumentar, já que vários participantes fazem um deslocamento e, por conseguinte, necessitam de acomodação.

Dentre os tipos de eventos existentes, destacam-se os eventos religiosos, que podem ser entendidos como a celebração de devoção ao santo específico de uma cidade ou região. Os fiéis se reúnem para rezar e agradecer por graças alcançadas, renovando a fé e a esperança em dias melhores.

Os eventos religiosos no Brasil têm muita adesão, já que o povo brasileiro é bastante devoto. O país tem várias festas religiosas populares, como a celebração de Nossa Senhora Aparecida, no Santuário de Aparecida em São Paulo, a festividade de Nossa Senhora de Nazaré no Pará, que é uma das mais conhecidas do país e suas novenas atraem milhões de fiéis para louvar e a adorar a referida santidade.

Regionalmente falando, no Nordeste, um dos estados mais populares por seus eventos religiosos é o Ceará. Durante todo o ano, a cidade de Juazeiro do Norte, conhecida pelo sacerdote católico, Padre Cicero, recebe inúmeros fiéis, assim como Canindé, que se destaca com a festa de São Francisco. Tais eventos, são responsáveis por potencializar o turismo religioso no Estado.

Entre as manifestações religiosas do Ceará, destacase também, a festa de Nossa Senhora das Candeias, realizada na cidade de Jaguaribe. O município está localizado às margens da BR 116, a aproximadamente 300 quilômetros da capital, Fortaleza, com população estimada em 34.317 mil habitantes, segundo o senso de 2012 (IBGE, 2014). O turismo tem sido potencializado na região, através de eventos culturais, esportivos, gas- tronômicos e religiosos.

Este estudo justifica-se por apontar o potencial religioso da festa para o turismo local, através da ocupação dos meios de hospedagem, pois o evento pode trazer oportunidades para os empresários e comunidade, possibilitando a melhoria dos serviços ou até mesmo a construção de novos meios de hospedagem no município.

O estudo tem relevância para os profissionais da hotelaria, uma vez que apresenta informações sobre a festividade e como o bem receber pode influenciar na fidelidade dos hóspedes, além de contribuir para o crescimento da economia. Este estudo também favorece os empresários, pois alerta quanto as possibilidades no mercado de turismo na região. Sendo assim, a pergunta de partida deste estudo foi: quais os impactos da festa de Nossa Senhora das Candeias nos meios de hospedagem de Jaguaribe?

Portanto, o objetivo geral da pesquisa foi analisar os impactos da festa de Nossa Senhora das Candeias nos meios de hospedagem de Jaguaribe. Os objetivos específicos foram: avaliar as relações dos meios de hospedagem com a equipe responsável pelo evento religioso; comparar a taxa de ocupação dos meios de hospedagem no período da festa com os demais meses do ano; identificar as estratégias de marketing utilizadas pelos meios de hospedagem na ocasião festiva; verificar forças e fraquezas dos meios de hospedagem na hospitalidade do hóspede e a visão do gestor quanto ao mercado hoteleiro.

Quanto aos aspectos metodológicos, tratou-se de uma pesquisa de campo, realizada através de entrevistas semiestruturadas, com análise qualitativa dos dados coletados. O universo da pesquisa foi composto pelos responsáveis dos meios de hospedagem de Jaguaribe. Para este estudo foram selecionados dois meios de hospedagem, duas pousadas, que se destacam por sua infraestrutura.

Este estudo apresenta seções sobre: conceitos e definições de eventos, assim como suas tipologias e abrangência; fundamentação teórica sobre turismo religioso e eventos religiosos; percurso metodológico para a obtenção dos dados; discussão dos resultados obtidos; considerações sobre a pesquisa.

\section{FUNDAMENTAÇÃO}

\subsection{Eventos - Conceitos e Classificações}

Existem diversos conceitos de eventos, mas nenhuma definição ecumênica. Martins (2007, p. 35) afirma que o acordo na conceituação "é dificultado pela própria 
natureza intrínseca da atividade: seu dinamismo e sua abrangência". A autora aponta ainda que "evento é todo fato inusitado que envolve pessoas".

Corroborando com a afirmação anterior, evento também pode ser compreendido como "qualquer acontecimento que foge à rotina, sempre programado para reunir um grupo de pessoas" (SENAC, 2000, p. 11). Ressalta-se a menção à programação, que está intrinsecamente relacionada à organização da intervenção, que tem papel relevante no cumprimento dos objetivos de qualquer evento.

Britto e Fontes (2002, p. 14) afirmam que um evento pode ser considerado como "a soma de esforços e ações planejadas com o objetivo de alcançar resultados definidos junto ao seu público-alvo". Planejar é a forma mais eficaz de atingir o sucesso de um evento, pois neste processo é possível traçar estratégias e planos que buscam minimizar e/ou evitar falhas na execução, apontando também alternativas para a solução de situaçõesproblema.

Segundo Zanella (2006, p. 21) "por sua complexidade, amplitude e importância, a promoção de um evento exige alta especialização técnica, experiência e especialização no tipo de evento que será realizado. Sua operacionalização fundamenta-se em um eficiente sistema de planejamento". Ainda segundo o mesmo autor:

\begin{abstract}
Evento é uma concentração ou reunião formal e solene de pessoas e/ou entidades realizada em data e local especial, com objetivo de celebrar acontecimentos importantes e significativos e estabelecer contatos de natureza comercial, cultural, esportiva, social, familiar, religiosa, científica, etc Zanella (2006 p. 1).
\end{abstract}

Segundo Bahl (2003), os eventos têm se destacado no setor econômico brasileiro. Mesmo com os grandes avanços tecnológicos, os eventos continuam sendo uma das alternativas mais viáveis para se estabelecer novos contatos no mercado, garantindo câmbio de informações e experiências entre os profissionais que atuam no segmento.

Considerando o viés econômico, Andrade (1999, p. 32) afirma que evento é um "fenômeno multiplicador de negócios pelo seu potencial gerador de novos fluxos de visitantes. Evento é todo fenômeno capaz de alterar determinada economia".

Os eventos podem ser classificados de acordo com a área de interesse, a saber: artísticos, científicos, culturais, cívicos, desportivos, folclóricos, de lazer, promocionais ou comerciais, sociais, turísticos, religiosos, governamentais, empresariais, educativos, cívicos e outros (MATIAS, 2010).
Segundo Britto e Fontes (2002), os eventos podem ser públicos (gratuitos) ou privados (necessitam de um investimento financeiro para garantir a participação). De acordo com a abrangência do público, os eventos podem ser: mundiais, internacionais, latinoamericanos, nacionais, regionais e municipais.

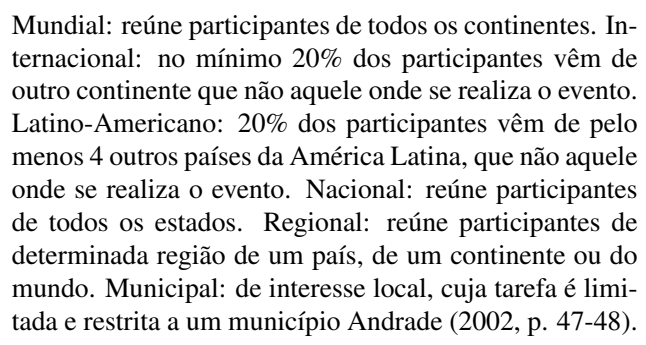

Mundial: reúne participantes de todos os continentes. Internacional: no mínimo $20 \%$ dos participantes vêm de outro continente que não aquele onde se realiza o evento. Latino-Americano: $20 \%$ dos participantes vêm de pelo menos 4 outros países da América Latina, que não aquele onde se realiza o evento. Nacional: reúne participantes de todos os estados. Regional: reúne participantes de determinada região de um país, de um continente ou do mundo. Municipal: de interesse local, cuja tarefa é limitada e restrita a um município Andrade (2002 p. 47-48).

Tenan (2006) aponta que quanto à frequência de realização, os eventos podem ser enquadrados em: permanentes (são realizados periodicamente), esporádicos (organizados de acordo com a demanda, não tem uma regularidade temporal), únicos (não se repetem) e de oportunidade (realizados em consonância com outros grandes eventos, como estratégia de divulgação).

Dentro da classificação de eventos, destaca-se os eventos religiosos, que segundo Britto e Fontes (2002), são eventos que marcam a devoção e a fé das pessoas, que tem o intuito de promover a religiosidade, resgatando tradições, como as procissões, as romarias, os retiros e as festas dos padroeiros.

Santos e Nunes (2005) afirmam que as festas religiosas constituem um dos principais momentos do catolicismo popular. Algumas cidades brasileiras são marcadas pelas agitações das novenas e procissões. A fé e a religião estão presentes no cotidiano das pessoas, independente da classe social, raça ou gênero.

\subsection{Eventos Religiosos e a Festa de Nossa Se- nhora das Candeias em Jaguaribe}

Os eventos religiosos têm muita visibilidade no país, o povo brasileiro tem muita fé, e cada Estado tem seu santo de maior devoção. Dentro deste contexto de eventos, as cidades passam a receber grandes fluxos de pessoas e a rede hoteleira tem que atender às necessidades destes visitantes, oferecendo serviços de qualidade, a fim de intensificar a hospitalidade.

Os eventos religiosos, incitam o turismo religioso, que pode ser entendido como o conjunto de atividades que envolvem sentimentos místicos ou suscitam a fé, a esperança e a caridade aos crentes ou pessoas vinculadas à religião (ANDRADE, 2002). É um momento em que ocorre um deslocamento da sua cidade para outra, 
a fim de participar de manifestações religiosas, que corroborem com a fé e a devoção.

O turismo religioso é motivado pela religiosidade das pessoas, de vivenciar a fé em lugares santos, marcados por milagres e bênçãos. De acordo com Andrade (2002, p. 79), depois do turismo de férias e de negócios, o segmento que mais está se destacando é o turismo religioso, uma vez que, "[...] além dos aspectos místicos e dogmáticos, as religiões assumem o papel de agentes culturais pelas manifestações de valores antigos, de intervenção na sociedade atual e de preservação no que diz respeito ao futuro dos indivíduos e das sociedades".

Dias e Silveira (2003), relatam que o turismo religioso contribui diretamente para a eficiência da economia local, promovendo novos postos de trabalhos diretos e indiretos para a população, aumentando o fluxo de consumo no comércio, rede hoteleira e outros.

Ansarah et al. (2000) declaram que Aparecida, cidade interiorana do estado de São Paulo, é referência no Brasil, no que tange ao turismo religioso de massa, pois recebe anualmente milhões de peregrinos. O santuário de Aparecida é conhecido nacionalmente e internacionalmente pela sua capacidade de transmitir aos fiéis uma energia positiva, um espírito novo aos visitantes.

Desde os primórdios, a religião, foi a força espiritual da sociedade e nenhum povo, historicamente falando, teve progressos distante de uma religião (CUNHA, 2003). A religião sempre foi a base da vida humana, das relações com as pessoas, principalmente com a família.

De acordo com Abreu e Coriolano (2003, p. 79), "as festas religiosas estão entre as mais fortes expressões da cultura brasileira, sendo significativa a quantidade e a diversidade de celebrações que acontecem, tornando-se lócus do turismo religioso". As festividades religiosas perpetuam as gerações, celebrando a vida, com fé e esperança.

"A fé apresenta uma nova missão para a vida, a aventura da abertura para uma realidade multidimensional" (BECKER, 2007, p. 21). A religião que cada pessoa se identifica, representa sua liberdade, sua visão do mundo, sua forma de viver a vida, e é ela que dá força para transpor os obstáculos do cotidiano.

"O turismo religioso insere-se no ramo da cultura, pois, ir a locais, santuários e igrejas representativas para qualquer religião, além dos aspectos dogmáticos, são também uma forma de conhecimento cultural" (ARAGÃO, 2014, p. 148). Conforme Gouthier (2000, p. 8) "as festas religiosas brasileiras têm sua origem no calendário de romarias e devoção dos Santos e Santas de Portugal, herança dos períodos históricos".
Os santos podem ser considerados como divindades que protegem o indivíduo e a comunidade contra os males e infortúnios. A relação entre o indivíduo e o santo baseiase num contrato mútuo, a promessa. Cumprindo aquele sua parte do contrato, o santo fará o mesmo. Promessas "são pagas" adiantadamente, para se obrigar o santo a retribuir sob a forma do benefício pedido (GALVÃO 1976 p. 31).

A fé e devoção de Jaguaribe é fortalecida através de Nossa Senhora das Candeias, também conhecida como Nossa Senhora da Purificação, pois ao mesmo tempo em que apresentava e consagrava seu único filho ao Senhor, se purificava.

A festa de Nossa Senhora das Candeias, é considerada um evento religioso, permanente, pois é realizada sempre do dia 23 de janeiro a 2 de fevereiro. Pode ser classificado como um evento público e regional, abrangendo devotos do estado do Ceará. O evento se inicia com o hasteamento da bandeira no dia 23. As novenas acontecem do dia 24 de janeiro a primeiro de fevereiro.

No dia 2 de fevereiro, se comemora o dia da Padroeira. Neste dia, ocorre uma procissão, às 17 horas, com saída da Igreja Matriz e percurso contemplando as tradicionais ruas do centro da cidade. Os cânticos e a iluminação das velas, renovam a fé da região, as roupas brancas usadas pelos participantes, buscam afirmar a paz. A festa é finalizada com uma queima de fogos que alegram e emocionam a todos.

Ainda no último dia de festividade, ocorre um leilão no parque de exposição da cidade, têm bingos organizados pela paróquia, apresentações de artistas locais, além de venda de comidas típicas, como baião de dois, vatapá, e a tradicional galinha caipira.

$\mathrm{Na}$ praça da cidade se instala também o parque de diversões com uma grande variedade de brinquedos, e ao lado da rodoviária, vendedores montam suas bancas e vendem roupas, calçados, brinquedos e outros. Durante o período da festa a cidade recebe muitos visitantes e é neste momento que a hospitalidade fará o diferencial na permanência do turista em Jaguaribe.

Não há um controle de quantas edições da festa de Nossa Senhora das Candeias já foram realizadas, segundo o sítio eletrônico da prefeitura de Jaguaribe, as novenas em homenagem à santidade já ocorriam na região, antes da igreja se tornar paróquia. O levantamento de fiéis, que participam da festividade, também não é contabilizado pela instituição religiosa, que tem o lema: "Construindo e Reconstruindo a História à Luz da Fé".

\section{METODOLOGIA}

A pesquisa é de caráter exploratório, com uma abordagem qualitativa. O método qualitativo possui um elo 
intrínseco entre o universo objetivo e a intangibilidade do sujeito, que não pode ser representado em números. Visa retratar e reconhecer os acontecimentos do mundo social, onde o método e sua acepção são os alvos principais da abordagem (MINAYO, 2008).

O cenário de pesquisa foi caracterizado por duas pousadas da cidade de Jaguaribe, de uma totalidade de cinco pousadas e um hotel. Foram escolhidas intencionalmente, as duas pousadas que possuíam melhor infraestrutura, ambas dispõem de estacionamento próprio, wifi, café da manhã, televisão de lcd, ar-condicionado e frigobar nos quartos, dentre outros serviços. O hotel não participou da pesquisa, por indisponibilidade de tempo.

Inicialmente foi realizada uma pesquisa bibliográfica sobre a temática em questão. Em seguida, a coleta dos dados foi realizada através de agendamento prévio, por meio de telefone, verificando a disponibilidade dos gerentes de cada empreendimento para realizar a pesquisa. A obtenção dos dados ocorreu através de uma entrevista semiestruturada, realizada no mês de junho de 2016, composta de seis questões. A entrevista foi gravada e as falas dos entrevistados foram transcritas para a realização da análise do discurso.

Gil (2008) ressalta que a entrevista é um procedimento em que o pesquisador se coloca diante do entrevistado e lhe faz questionamentos, objetivando a aquisição de dados que interessam ao estudo. A entrevista é, portanto, uma forma de interação social.

\section{RESULTADOS E DISCUSSÃO}

Nesta seção, apresentam-se os resultados coletados através de entrevistas e respectivas discussões. A pesquisa foi realizada com gestores de duas pousadas, os entrevistados responderam a seis perguntas. $\mathrm{O}$ primeiro questionamento da entrevista versou sobre a elevação dos preços nos meios de hospedagem com a realização da Festa de Nossa Senhora das Candeias, como resultado obteve-se que os preços se mantêm, como pode ser observado na fala do entrevistado, abaixo.

\footnotetext{
O preço da diária é um só, dependendo da época a gente faz é baixar o valor, eu tenho um tarifário, e a gente sempre o segue. Não me aproveito da situação, em período de eventos, a gente não inflaciona o preço, pois é lotação garantida [...]. Qualquer evento que tenha na cidade, normalmente, influencia diretamente na taxa de ocupação da pousada (POUSADA 1, PESQUISA DIRETA, 2016).
}

Quanto aos preços, é interessante ressaltar que os mesmos se mantêm em épocas festivas, o que é bom para o visitante. Em contrapartida, nas ocasiões em que há realização de eventos, os meios de hospedagem, em geral, principalmente nas capitais, elevam seus preços para garantir maior rentabilidade, uma vez que, em alguns períodos do ano, o empreendimento hoteleiro pode ter sua ocupação bastante reduzida.

Kotler e Keller (2004) afirmam que o preço é o valor monetário aplicado ao produto e que o consumidor faz uma análise do mesmo, se é viável ou não, logo, as empresas devem estimar preços condizentes com o mercado. Para Nunes (2006), o preço é fator fundamental no momento de decidir por um produto ou serviço.

Vale ressaltar que o evento também contribui para a economia local de Jaguaribe, com a geração de empregos temporários, aumento das vendas no comércio, e também nos bares e restaurantes da cidade, desenvolvendo assim outros setores da economia.

A segunda questão teve como objetivo identificar se existe um planejamento específico, com definição de estratégias de marketing para o período da festa, onde pôde-se observar que não há um consenso sobre o planejamento e organização para a festividade, como pode ser verificado na transcrição das falas abaixo.

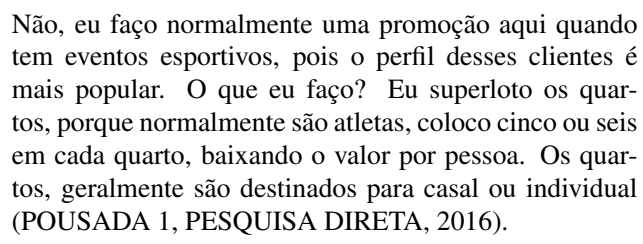

"Geralmente nós fazemos planejamento, em geral, nesse tipo de situação a gente faz, para acomodar as pessoas que procuram os serviços da pousada nesse período" (POUSADA 2, PESQUISA DIRETA, 2016). O primeiro empreendimento não se preocupa em planejar suas ações para elevar a taxa de ocupação no período da festa. Superlotar a unidade habitacional para atender a demanda, confronta um dos objetivos da hotelaria, que é o conforto. Já o segundo meio de hospedagem busca planejar suas ações para garantir mais lucros.

Como o evento ocorre anualmente na cidade, deveriam ser feitas algumas promoções, como elaboração de pacotes promocionais para as famílias ou outros serviços diferenciados durante este período, para atrair e fidelizar os hóspedes. Estas seriam estratégias a serem traçadas nos momentos de planejamento. Os meios de hospedagem poderiam ainda contribuir para a divulgação do evento, visando atingir um público maior.

Segundo Kotler e Keller (2004, p. 142), a "promoção cobre todas aquelas ferramentas de comunicação que fazem chegar uma mensagem ao público-alvo". A promoção de um produto ou serviço envolve estratégias que os empreendimentos aplicam para que seus produ- 
tos sejam os escolhidos pelo consumidor, dentre as opções existentes. Trata-se de uma estratégia de marketing bastante eficiente.

A terceira pergunta procurou investigar a taxa de ocupação do meio de hospedagem antes da festa e no período da mesma, buscando perceber se existe uma diferença entre o número de clientes que procuram o meio de hospedagem em qualquer época do ano e especificamente na ocasião do evento.

Durante a festa as vendam melhoram em torno de $25 \%$, porque a pousada recebe os representantes comerciais. Nos outros períodos do ano, posso afirmar que os viajantes na cidade são poucos. A clientela maior durante o ano é de professores, grande parte, hoje mesmo estamos aqui com os oito quartos ocupados por professores de outras cidades (POUSADA 1, PESQUISA DIRETA, 2016).

"Geralmente, a taxa de ocupação no dia a dia é de $30 \%$ a $40 \%$. No período da festa, a taxa é de aproximadamente 100\%" (POUSADA 2, PESQUISA DIRETA, 2016). Como pode ser observado, a festividade influencia na taxa de ocupação dos meios de hospedagem, em questão. Um dos meios de hospedagem afirma que o evento contribui para a ocupação significativa do empreendimento, e o outro aponta que há uma maior demanda de um público específico na ocasião, quando comparado com períodos não festivos.

Observa-se que apesar dos impactos positivos da festa sobre as duas pousadas, as taxas de ocupação são divergentes. Essas diferenças, podem estar atreladas às estratégias de mercado utilizadas pelos empreendimentos, ou até mesmo pela hospitalidade, a procura pode ser maior em um empreendimento que no outro, pois um pode receber o hóspede de forma mais acolhedora, comparativamente falando.

A quarta questão buscou conhecer a opinião da gestão quanto à visão do mercado hoteleiro da cidade de Jaguaribe. Notou-se que devido à baixa procura por serviços de hospedagem, um dos empreendimentos tem baixa rentabilidade, já outro aponta que a cidade deveria investir mais em turismo para aumentar o fluxo de visitantes na região, como pode ser observado nas falas abaixo.

[...] Estamos há quatro anos no mercado, e o lucro que dá aqui é tão pouco que não dá nem para realizar novos investimentos no empreendimento, é repor alguma coisa e só. Mantenho cinco funcionários, todos eles com carteira assinada, uma carteira assinada custa caro, então está dando para pagar as despesas e o que sobra não dá para muita coisa (POUSADA 1, PESQUISA DIRETA, 2016).

"A gente sempre está buscando fazer melhorias, para poder atingir as expectativas do cliente, eu acho que a cidade poderia investir mais em eventos, e na divulgação dos mesmos" (POUSADA 2, PESQUISA DIRETA, 2016).

Observa-se que os empresários do mercado hoteleiro da cidade, ainda tem uma visão muito simbólica sobre o próprio segmento em que estão inseridos, faltam informação e qualificação a esses gestores, o conhecimento que eles têm foi adquirido no seu dia a dia. Parcerias de mercado, estratégias de marketing e gestão seriam essenciais para a maximização de resultados desses empreendimentos.

Há o reconhecimento da importância econômica da realização de eventos na cidade, em uma das falas. De fato, seria relevante, que órgãos públicos e privados pensassem em um calendário de eventos que garantisse o fluxo de visitantes na cidade, em mais meses do ano.

De acordo com Kober (2004, p. 154) "qualificação profissional é a preparação do cidadão através de uma formação profissional para que ele possa aprimorar suas habilidades para executar funções específicas demandadas pelo mercado de trabalho".

Para Araújo (2009, p. 68), "o mercado de trabalho brasileiro sofre com a escassez de profissionais qualificados [...], a falta de habilidades técnicas é de longe, o principal entrave para o preenchimento de determinadas posições".

A quinta pergunta analisou se existe uma relação de trabalho em equipe entre os meios de hospedagem e a organização da Festa de Nossa Senhora das Candeias, constatou-se que não existe nenhum vínculo, como pode ser observado a seguir.

\footnotetext{
Não, o vínculo que eu tenho é com secretário de esporte, quando tem esses eventos esportivos, que por sinal é uma parceria que eu tenho com ele [.,.] Uma mão lava a outra, normalmente eu dou oito hospedagens para os árbitros e ele indica a pousada para os demais participantes do evento. Agora, vínculo com essas outras entidades, como a igreja, eu não tenho (POUSADA 1, PESQUISA DIRETA, 2016).

\begin{abstract}
Não, não está havendo esse entrosamento, por exemplo, para o Jaguar Fest, a Festa de Nossa Senhora das Candeias, a vaquejada e outras festas, todos deveriam estar juntos para divulgar, porque outros eventos, em outras cidades do interior são bem divulgados. O carnaval de Aracati tem boa repercussão, porque deram todo um aparato para que ele fosse divulgado [...] (POUSADA 2, PESQUISA DIRETA, 2016).
\end{abstract}

Como citado pelos entrevistados, não há nenhum trabalho integrado da organização da festa com os meios de hospedagem da cidade, não é feito nenhum contato prévio para articular ações em prol do públicoalvo do evento. Seria ideal que a organização buscasse 
os meios de hospedagem como apoio na realização da festividade, já que há a necessidade de acomodar os visitantes que se encontram na cidade, devido a programação do evento, além de solicitar reforço na divulgação da comemoração, e, por conseguinte, serviços dos meios de hospedagem.

O último questionamento visou detectar o ponto positivo e negativo dos meios de hospedagem, demostrando suas forças e fraquezas na hospitalidade dos hóspedes, como podem ser observadas nas falas dos entrevistados, a seguir.

\section{O ponto positivo é que estamos sempre vendo pessoas diferentes, e é muito gratificante quando a pessoa chega aqui [...] todo dia de manhã cedo, 6:00 horas, eu estou aqui para ajudar a servir o café, apesar de haver duas fun- cionárias de manhã na hora do café, mas eu me sinto tão bem em servir, vir aqui conversar com os clientes, conto uma história, eles contam outra e a gente vai sempre tro- cando as ideias. O ponto negativo é que é triste quando não tem nenhum cliente na pousada [...] (POUSADA 1, PESQUISA DIRETA, 2016).}

"O objetivo da gente é sempre atender da melhor maneira possível o cliente, buscando inovar, trabalhar com qualidade, acho que é isso que a gente tem que fazer [...]" (POUSADA 2, PESQUISA DIRETA, 2016). O ponto positivo que pode ser destacado é a possibilidade de conhecer novas pessoas e culturas, além de buscar atender o cliente da melhor maneira possível.

O ponto negativo apontado é a baixa taxa de ocupação em alguns períodos do ano, que não afeta o processo de hospitalidade do hóspede. Neste caso, os gestores devem buscar estratégias para garantir uma taxa de ocupação mínima em seus meios de hospedagem. Reconhecer as potencialidades e as fraquezas é essencial para traçar planos de prospecção de clientes.

\section{CONSIDERAÇÕES FINAIS}

O estudo teve como propósito analisar os impactos que a Festa de Nossa Senhora das Candeias causa nos meios de hospedagem da cidade de Jaguaribe. Observou-se que há uma forte interferência na taxa de ocupação dos meios de hospedagem, durante o período do evento, isso favorece consequentemente a economia da localidade, beneficiando os comerciantes, empresários e comunidade de forma geral. Tendo em vista o exposto, pode-se afirmar que o objetivo geral da pesquisa logrou êxito e que a pergunta de partida foi respondida.

Os objetivos específicos foram alcançados, pois analisou-se a taxa de ocupação dos meios de hospedagem antes e durante a festa, identificando que há um aumento na mesma. Verificou-se que poucas são as estratégias de marketing usadas pelos meios de hospedagem para atender a demanda desse evento, a divulgação dos serviços e promoções são insuficientes para atrair o público-alvo. Vale ressaltar a importância dada à hospitalidade pelos gestores, no processo de estada do visitante nos meios de hospedagem, porém faz-se necessário uma qualificação para melhor compreensão do mercado hoteleiro.

A comunicação entre a organização do evento e os meios de hospedagem deve melhorar. É de suma importância o trabalho integrado da paróquia com os empreendimentos hoteleiros, para o acolhimento das pessoas na cidade, fazendo um planejamento, que atenda às necessidades dos visitantes e os encantem no período de permanência no município.

Uma devolutiva dos resultados foi dada aos envolvidos na pesquisa, a fim de potencializar as próximas ações da Festa de Nossa Senhora das Candeias, para que o evento aos poucos possa tomar proporções maiores, atingindo públicos de outras regiões e se tornando referência no turismo religioso, este, sem dúvidas, foi um excelente contributo para o município. Recomendouse também o controle quantitativo das edições da festa, assim como o número de fiéis participantes na ocasião, para classificações mais abrangentes do evento.

Este estudo sugere ainda outras possibilidades de pesquisa na cidade de Jaguaribe, como um estudo de caso sobre o Jaguar Fest, o carnaval fora de época do município, uma análise do tradicional festival de Queijo Coalho, as vaquejadas da região como produto turístico, dentre outras.

\section{REFERÊNCIAS}

ABREU, T. N. M. d.; CORIOLANO, L. N. M. T. Os centros de romaria do ceará e o turismo religioso. O turismo de inclusão e o desenvolvimento local, Fortaleza: FUNECE, v. 1, n. 1, p. 78-95, 2003.

ANDRADE, J. V. Turismo: Fundamentos e

Dimensões. São Paulo: Ática, 2002.

ANDRADE, R. B. Manual de eventos. ampl. Caxias do Sul: EDUCS, 1999.

ANSARAH, M. G. d. R. et al. Turismo: segmentação de mercado. São Paulo, 2000. 20-23 p.

ARAGÃO, I. R. Turismo cultural-religioso, festa católica e patrimônio em são cristóvão-sergipe-brasil. PASOS. Revista de Turismo y Patrimonio Cultural, 
EVENTOS RELIGIOSOS: A FESTA DE NOSSA SENHORA DAS CANDEIAS E SEUS IMPACTOS NOS MEIOS DE HOSPEDAGEM DE JAGUARIBE - CEARÁ

Universidad de La Laguna, v. 12, n. 1, p. 145-158, $\quad$ SANTOS, M. F. J.; NUNES, V. M. M. Na trilha dos 2014. passos do senhor: A devoção ao senhor dos passos de

ARAÚJO, T. Raridades no mercado. São Paulo, 2009.

BAHL, M. Turismo e Eventos. Curitiba, 2003. são cristovão/se. Revista da Fapese de Pesquisa e Extensão, v. 2, p. 97-110, 2005.

SENAC. Eventos: Oportunidades de novos negócios. Rio de Janeiro, 2000.

BECKER, E. A negação da morte. Rio de Janeiro, 2007.

BRITTO, J.; FONTES, N. Estratégias para eventos: uma ótica do marketing e do turismo. [S.1.]: Aleph, 2002.

TENAN, I. P. S. Eventos. São Paulo, 2006.

ZANELLA, L. C. Manual de organização de eventos: planejamento e operacionalização. [S.1.]: Atlas, 2006.

CUNHA, L. Introdução ao Turismo. Lisboa, 2003.

DIAS, R.; SILVEIRA, E. J. S. da. Turismo religioso: ensaios e reflexões. [S.1.]: Alínea Editora, 2003.

GALVÃO, E. E. Santos e visagens: um estudo da vida religiosa de Itá, Baixo Amazonas. Brasília: Editora Nacional, 1976.

GIL, A. C. Métodos e técnicas de pesquisa social. São Paulo: 6. ed. Ediitora Atlas SA, 2008.

GOUTHIER, J. Fé faz o brasil se multiplicar. Caderno de Turismo. Jornal do Brasil, v. 8, n. 1, p. 8, 2000.

IBGE. Instituto Brasileiro de Geografia e Estatística. 2014. Disponível em: <ftp: //ftp.ibge.gov.br/Estimativas_de_Populacao/ Estimativas_2014/estimativa_dou_2014.pdf>. Acesso em: 05 jun. 2016.

KOBER, C. M. Qualificação profissional: uma tarefa de Sísifo. [S.1.]: Forward Movement, 2004.

KOTLER, P.; KELLER, K. L. Administração de marketing. São Paulo, 2004.

MARTINS, V. Manual prático de eventos. São Paulo, 2007.

MATIAS, M. Organização de eventos: procedimentos e técnicas. [S.1.]: Editora Manole, 2010 .

MINAYO, M. C. S. O desafio do conhecimento. Pesquisa qualitativa em saúde. São Paulo, 2008.

NUNES, J. O toque de midas no varejo. 2006. Disponível em: <http://josemauronunes.blogspot.com/ 2008/10/o-toque-de-midas-no-varejo.html>. Acesso em: 24 jun. 2016. 